\title{
Dissimilation of 1,2-propanediol by rumen micro-organisms
}

\author{
By J. W. CZERKAWSKI AND GRACE BRECKENRIDGE \\ Hannah Research Institute, Ayr KA6 ${ }_{5} \mathrm{HL}$
}

(Received 10 $\mathcal{f u l y}$ 1972-Accepted I6 October 1972)

\begin{abstract}
I. The main products of fermentation of $\mathrm{r}, 2$-propanediol were $n$-propanol and propionic acid, but variable amounts of acetic acid and carbon dioxide were also formed. The concentrations of an intermediate propionaldehyde increased and then decreased.

2. A tentative scheme is suggested, showing that 1,2-propanediol is first dehydrated to propionaldehyde, which is then reduced to $n$-propanol. The scheme also explains the formation of propionic and acetic acids and shows how the metabolism of 1,2 -propanediol is related to that of thamnose.

3. Experiments with samples of rumen contents from animals on various diets showed that $\mathrm{r}, 2$-propanediol was metabolized most rapidly when the animals were given molassed sugar-beet pulp. The rates of dissimilation of the diol increased with the concentration of rumen contents and with the concentration of substrate.

4. The dissimilation of 1,2 -propanediol by rumen micro-organisms resulted in an increased uptake of hydrogen. The metabolic hydrogen, arising from the inhibition of methane production by chloroform, appeared to be better utilized than the gaseous hydrogen.

5. Oxygen gas did not affect the utilization of 1,2 -propanediol, but the diol increased the uptake of oxygen by the rumen contents. The hydrogen and carbon balances were better when I,2-propanediol was incubated anaerobically than in the presence of oxygen.
\end{abstract}

It was shown by Waldo \& Schultz (1960) that I,2-propanediol is a gluconeogenic substance and that its administration to ruminant animals results in an increase in blood glucose and in an increased production of propionic acid in the rumen. Emery, Burg, Brown \& Blank (1964) confirmed these findings and found that the metabolism of $\mathrm{I}, 2$-propanediol in the rumen results in an increase in the rumen concentration of propionic acid and a decrease in acetic and butyric acids. Later, Emery, Brown \& Black $(1967)$ used $\left[2-{ }^{14} \mathrm{C}\right]-1,2$-propanediol-2 and recovered $44 \%$ of activity in carbon dioxide, $12 \%$ in milk and up to $7 \%$ in urine. They concluded that a large proportion of the diol was absorbed from the rumen intact and that some was metabolized in the rumen to propionic acid-another glucogenic substance.

Recently, Czerkawski \& Breckenridge (I972) observed that the metabolic pathways involved in the dissimilation of I,2-propanediol by rumen micro-organisms were complex and related to those of rhamnose. The effect of dietary 1,2-propanediol upon the energy metabolism of sheep was studied by Clapperton \& Czerkawski $(1972 a)$. These studies confirmed that the infusion of I,2-propanediol into the rumen resulted in an increase in propionic acid concentration and a decrease in acetic acid in the rumen and that $40 \%$ of the administered diol was metabolized to carbon dioxide. The diol also resulted in small but consistent inhibition of methane production. The diol disappeared rapidly from the rumen, but it was not clear whether it was absorbed as such from the rumen or converted into products that were not measured.

I,2-Propanediol can be metabolized in animal tissues such as the liver, and by certain micro-organisms. In experiments with rats, it was shown by Rudney (1950, 
1954) that 1,2 -propanediol phosphate is an intermediate in the metabolism of acetone, and that the carbon from I,2-propanediol can contribute substantially to the formation of liver glycogen. Lactaldehyde can also lead to increases in liver glycogen and it might be involved in pathways leading from lactate to propanediol (Shull \& Miller, I960). The most extensive studies of metabolism of I,2-propanediol, mainly in Aerobacter aerogenes, were made by Abeles and co-workers. It was concluded that the dehydration of I,2-propanediol to propionaldehyde appears to be an intramolecular oxidation-reduction reaction requiring vitamin $\mathrm{B}_{12}$ coenzyme (Abeles \& Lee, I96I) and that the coenzyme serves as hydrogen carrier (Brownstein \& Abeles, I96I) in the dehydratase system that also involves monovalent cations (Toraya, Sugimoto, Tamao, Shimizu \& Fukui, r97I).

The object of our work was to study the metabolism of I,2-propanediol in the rumen in greater detail, with particular emphasis on the end-products and upon the involvement of the metabolism of the diol in the economy of metabolic hydrogen in the rumen. The first part of the paper is concerned with the products of fermentation of 1,2 -propanediol by rumen micro-organisms and an attempt is made to demonstrate the metabolic pathways involved. The second part is an investigation of the factors that affect the metabolism of 1,2 -propanediol by rumen micro-organisms.

\section{EXPERIMENT AL}

Animals and diets. In most experiments samples of rumen contents were obtained from sheep that were given $500 \mathrm{~g}$ molassed sugar-beet pulp at 09.00 hours and $350 \mathrm{~g}$ hay at 16.00 hours. The samples were taken before the morning feed as described previously (Czerkawski \& Breckenridge, 1969) and strained through four layers of cotton gauze. In some experiments, where comparison was made of the changes in the fermentative capacity with diet, samples of rumen contents were obtained from sheep or cows that had been on a given regimen for at least 3 weeks. As a rule, the samples were taken before the morning feed.

Incubation procedures. Incubations were made in the artificial rumen described by Czerkawski \& Breckenridge ( 1969 ): samples of rumen contents were diluted as required with buffer solutions (McDougall, 1948) to a total volume of $500 \mathrm{ml}$, and incubated for up to $8 \mathrm{~h}$ at $39^{\circ}$ in vessels through which a mixture of carbon dioxide and nitrogen $(5: 95)$ was bubbled in a closed system. Some samples were incubated for short periods of time in syringes in a modified system described by Czerkawski \& Breckenridge (1970).

Analytical techniques. Most of the analytical techniques have been described previously (Czerkawski \& Breckenridge, 1969, 1972). The concentrations of volatile fatty acids in the reaction mixtures were determined essentially by the method of Cottyn \& Boucque (1968) using a Pye I04 gas chromatograph and Carbowax columns at $145^{\circ}$. It was possible to determine the concentration of 1,2 -propanediol under the same conditions. The diol emerged between isobutyric and butyric acid. The concentrations of 1,2 -propanediol in some experiments were also measured by the colorimetric method of Jones \& Riddick (1957). 
Table I. Net production of volatile fatty acids, neutral $C_{3}$ compounds and carbon dioxide, and inhibition of methane production (mmol) during incubation for 4 h of $\mathrm{I}, 2$-propanediol with rumen contents from sheep given sugar-beet pulp

(Rumen contents $(200-300 \mathrm{ml})$ and artificial saliva $(200-300 \mathrm{ml})$ were incubated with $\times \cdot 0-1 \cdot 5 \mathrm{~g} \mathrm{I,2-}$ propanediol and the results were corrected for endogenous fermentation)

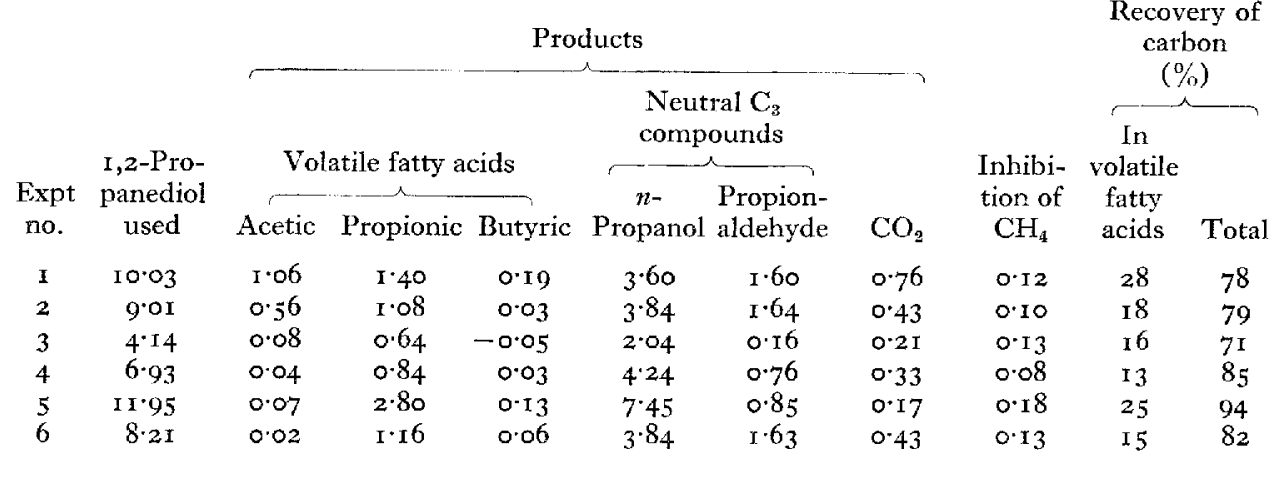

The concentrations of $n$-propanol and propionaldehyde were determined as follows.

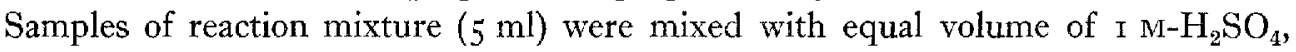
distilled slowly in a microdistillation apparatus and $5 \mathrm{ml}$ of distillate were collected. Virtually all the $n$-propanol and the propionaldehyde distilled over under these conditions. The distillate was injected on the same Carbowax columns that were used for volatile fatty acid analysis; the columns were operated at $70^{\circ}$. Under these conditions, the propionaldehyde peak emerged after $1 \mathrm{~min}$, and $n$-propanol peak emerged after 5 min. The amounts of propionaldehyde were estimated independently by the diffusion method for lactic acid (Conway, 1962) in which the oxidizing agent was omitted. 'The concentrations of lactaldehyde (as total aldehyde) were determined by titration (Huff, r959).

The concentration of acrylic acid was determined on composite gas-liquid chromatographic columns as described by Noble \& Czerkawski (1972) and the gases were analysed as described by Czerkawski \& Clapperton (ıg68).

\section{RESULTS}

Products of the metabolism of $\mathrm{I}, 2$-propanediol by rumen micro-organisms

Production of gases and volatile fatty acids. It was shown previously (Czerkawski \& Breckenridge, 1972) that the dissimilation of 1,2 -propanediol was accompanied by the production of propionic acid and a variable production of acetic acid. The concentrations of butyric acid were never significantly different from those of controls and there was invariably a small and consistent inhibition (10-30\%) of endogenous methane production. The present experiments confirmed these findings fully, as shown by some of the results summarized in Table $\mathrm{I}$. Propionic acid was the main known product, the amounts of acetic acid produced were variable and there were no significant amounts of butyric acid produced. Clearly, the volatile fatty acids accounted 
for only a small proportion of the substrate utilized. The fermentation of r,2-propanediol was accompanied by the production of carbon dioxide and a small but consistent inhibition of methane production. The only other product measured during the initial experiments was apparently lactic acid as determined by the diffusion method of Conway ( 1962 ); in this method, the acid is oxidized to acetaldehyde and determined as such. However, most of this apparent lactic acid that was formed during metabolism was subsequently shown to be propionaldehyde.

Production of propionaldehyde and $\mathrm{n}$-propanol. It was suspected that propionaldehyde might be one of the products of dissimilation of I,2-propanediol since it was observed that there was a consistent discrepancy between the concentrations of I,2-propanediol determined by gas-liquid chromatography and those determined by the colorimetric method of Jones \& Riddick (1957). The colorimetric method invariably gave higher results, except in samples at the beginning and at the end of incubation. In this method the diol is dehydrated to propionaldehyde or allyl alcohol and these then react with ninhydrin. Calculations of hydrogen balance indicated that hydrogen was used when propanediol was metabolized (production of propionic acid and inhibition of methane production without accumulation of hydrogen) and it was concluded that much of the unaccounted substrate carbon must have been converted to a product that was more reduced than I,2-propanediol. One possibility considered was an increase in lipid synthesis. In a typical experiment, the lipid synthesized in the control vessel at the end of incubation amounted to $7 \mathrm{mg}$ and in the vessel in which $\mathrm{I} \circ \mathrm{O} \mathrm{g} \mathrm{I}, 2$-propanediol had been fermented it amounted to $22 \mathrm{mg}$. In another experiment the corresponding values were 5 and $\mathrm{I} 2 \mathrm{mg}$ respectively. These amounts of lipids synthesized during incubation could account for only about I \% of substrate utilized. Other experiments, in which the particulate matter was isolated quantitatively from samples taken during incubation, showed that only very small amounts of propanediol could have been converted to microbial cell material.

It was shown that propionaldehyde was one of the products of metabolism of I,2-propanediol by rumen micro-organisms as follows. It could be readily distilled and it reacted with diphenylhydrazine to give a product with a melting point that differed little from the published value for the product of reaction of propionaldehyde with diphenylhydrazine $\left(155^{\circ}\right)$. It reacted with semicarbazide, the distillate had the typical fruity smell of propionaldehyde and on gas-liquid chromatography at $70^{\circ}$ it had the same retention volume as that of known samples of propionaldehyde. It was subsequently determined by gas-liquid chromatography or by the lactate method of Conway (1962) in which the oxidizing agent was omitted.

Although the presence of propionaldehyde in the products of the metabolism of propanediol improved the recovery of carbon, the recoveries were still unsatisfactory, ranging from 20 to $44 \%$. It seemed that the missing product must be a volatile compound possibly related to propionaldehyde, since the concentrations of the aldehyde initially increased and then diminished during the incubation. The alcohol $n$-propanol seemed a strong possibility and its presence could be demonstrated by gas-liquid chromatography at $70^{\circ}$. Its identity was established by oxidation to propionic acid with $\mathrm{KMnO}_{4}$ (Vogel, I95 I). Propionic acid was formed in good yields (80-90\%). The 

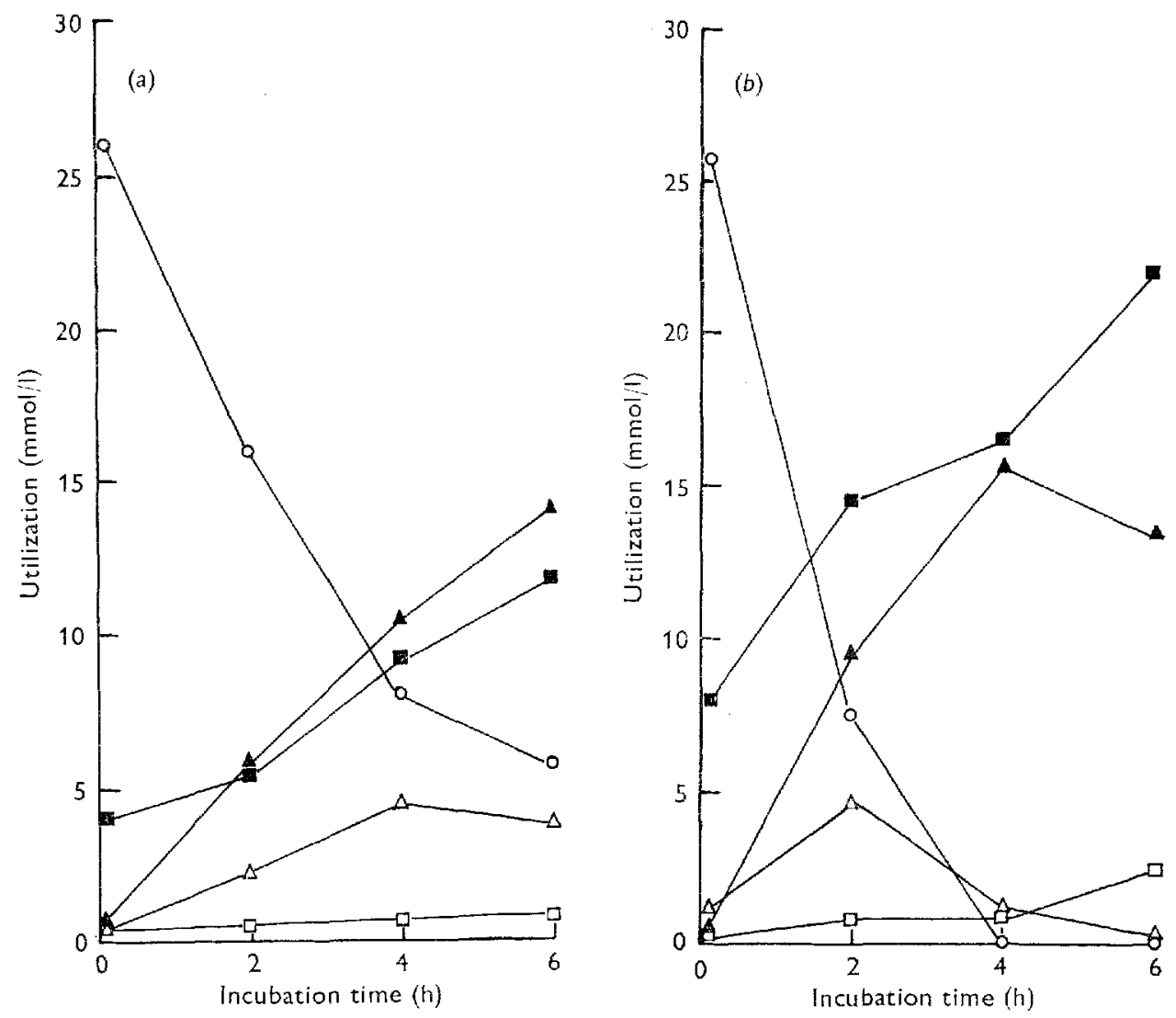

Fig. I. Utilization of 1,2 -propanediol ( $\bigcirc)$, production of methane $(\square)$, propionaldehyde $(\Delta)$, $n$-propanol (A) and propionic acid (E) by rumen micro-organisms from sheep during incubation in vitro. The concentrations of rumen contents in the incubation mixture were $200 \mathrm{ml} / 500 \mathrm{ml}(a)$ and $400 \mathrm{ml} / 500 \mathrm{ml}(b)$.

results in Table I showed that $n$-propanol was indeed the main product of the fermentation of propanediol and that when the formation of aldehyde and alcohol was taken into account the recoveries of substrate carbon were between $7 \mathrm{I}$ and $94 \%$.

The time-course of fermentation of propanediol, where 200 and $400 \mathrm{ml}$ of rumen contents were incubated with $\mathrm{I}_{5} 5 \mathrm{~g}$ propanediol and artificial saliva to $500 \mathrm{ml}$, are shown in Figs $\mathrm{I} a$ and $b$. With the lower concentration of rumen contents (Fig. I $a$ ) some substrate remained at the end of incubation. The concentration of propionaldehyde reached a maximum 4 h after the start. With the high concentration of rumen contents (Fig. $\mathrm{I} b$ ) all the substrate disappeared in $4 \mathrm{~h}$ and this was parallelled by relatively rapid disappearance of propionaldehyde after reaching a maximum after $2 \mathrm{~h}$ of incubation. The concentration of $n$-propanol decreased between 4 and $6 \mathrm{~h}$ of incubation and this was reflected by an increase in the production of propionic acid and methane during the same interval. This agreed with previous observations (Czerkawski \& Breckenridge, 1972) that an incubation of $n$-propanol with rumen 
contents resulted in production of propionic acid and a stoichiometric amount of methane.

Formation of minor products. Two substances were considered as likely intermediates in the metabolism of I,2-propanediol-lactaldehyde and acrylic acid. Lactaldehyde can be reduced to I,2-propanediol in rat liver (Ting, Sellinger \& Miller, I964) and it was of interest to determine whether this reaction or its reverse might take place in the rumen. A sample of lactaldehyde was prepared from threonine by the method of Huff \& Rudney (I959). When $5.9 \mathrm{mmol}$ of this sample were incubated with $200 \mathrm{ml}$ of rumen contents diluted to $500 \mathrm{ml}$ with buffer solution (McDougall, 1948), more than half disappeared in $8 \mathrm{~h}$, but only $20 \%$ of the substrate was converted to volatile fatty acids $(0.3 \mathrm{mmol}$ acetate and $0.2 \mathrm{mmol}$ propionate). The concentrations of lactaldehyde were estimated approximately in reaction mixtures by measuring the difference between the total and volatile aldehydes. The results were very variable when I,2-propanediol was incubated with rumen contents. The concentration of the apparent lactaldehyde was different from zero in only three out of seven experiments, and this occurred only after $\mathrm{I}-3 \mathrm{~h}$ of incubation. The mean concentration for the three experiments was $0.25 \mathrm{mmol} /$ vessel. This amount was small compared with 3-5 mmol diol used, and it was concluded that lactaldehyde is quantitatively not important in the metabolism of 1,2-propanediol in the rumen, but the results did not preclude the possibility that lactaldehyde might be an intermediate and could become important under certain conditions, such as the lack of reducing power.

The concentrations of acrylic acid were determined more accurately than those of lactaldehyde. The maximum concentrations observed were between 0.04 and $0.06 \mathrm{~m}$ $\mathrm{mol} /$ vessel, and often none could be detected. Acrylic acid is an important intermediate in the direct reductive pathway of formation of propionic acid from pyruvate (Ladd \& Walker, I959) and it could also play a part in the metabolism of I,2-propanediol, athough quantitatively, it did not appear important in the present experiments.

\section{Factors affecting the metabolism of I,2-propanediol by rumen micro-organisms}

Effect of diet on the capacity of rumen contents to dissimilate I,2-propanediol. In this series of experiments, samples of rumen contents were strained and incubated in syringes (Czerkawski \& Breckenridge, 1970) either with no addition (control) or with glucose $(2 \mathrm{mg} / \mathrm{ml}$, reference) or with I, 2-propanediol $(2 \mathrm{mg} / \mathrm{ml})$. Some of the pertinent results are summarized in Table 2 . The capacity of the rumen contents to ferment glucose, as shown by the net amounts of total volatile fatty acids formed, varied widely with the type of diet. When the rumen contents were incubated with I,2-propanediol, the production of three-carbon metabolites, that is propionic acid, propionaldehyde plus $n$-propanol was small with roughage rations but was much greater with the concentrate rations. The rates of production of the three-carbon metabolites were parallel with the rates of disappearance of the diol. Although the acid production from glucose by the rumen contents from sheep given molassed sugar-beet pulp was not exceptionally high (compare flaked maize-hay-barley diet), the rumen contents from sheep given the pulp showed the greatest capacity to ferment I,2-propanediol. 
Table 2. Capacity of various samples of rumen contents to

$$
\text { ferment } 1,2-\text { propanedial in } 4 h
$$

Total volatile

fatty acids

produced from

Diet

(r) Hay

(2) Dry grass cube

(3) Concentrate-hay

(4) Goat mix

(5) Flaked maize-hay-barley

(6) Molassed sugar-beet pulp

$$
\text { glucose }
$$

(mmol/l)

$8 \cdot 1$
$13 \cdot 8$
$3 \cdot 7$
$12 \cdot 3$
$86 \cdot 4$
$9 \cdot 9$

$13 \cdot 8$

$3 \cdot 7$

$86 \cdot 4$

$9 \cdot 9$
Total $\mathrm{C}_{3}$

substances produced from propanediol $(\mathrm{mmol} / \mathrm{i})$

I. Sheep given hay $(600 \mathrm{~g})$ at 09.00 and 16.00 hours.

2. Sheep given a dry grass cube (Czerkawski, 1966) $45^{\circ} \mathrm{g}$ at 09.00 hours, and $45^{\circ} \mathrm{g}$ and $\mathrm{I} 5^{\circ} \mathrm{g}$ hay at 6.00 hours.

3. Cows given $\mathrm{I}_{4} 4 \mathrm{~kg}$ concentrate and $3 \cdot 2 \mathrm{~kg}$ hay, twice daily.

4. Sheep given $290 \mathrm{~g}$ goat mix and $250 \mathrm{~g}$ hay at 09.00 and $\mathrm{I} 6.00$ hours.

5. Sheep given mixture of flaked maize $180 \mathrm{~g}$, hay $100 \mathrm{~g}$ and barley $720 \mathrm{~g}$.

6 . Sheep given sugar-beet pulp $(500 \mathrm{~g})$ at 09.00 hours and hay $(35 \circ \mathrm{g})$ at 16.00 hours.

Table 3. Effect of substrate concentration upon the fermentation of 1,2-propanediol by rumen contents from sheep given sugar-beet pulp

\begin{tabular}{|c|c|}
\hline $\begin{array}{c}\text { Substrate } \\
\text { concentration } \\
\text { (mmol/vessel *) }\end{array}$ & $\begin{array}{l}\text { Utilization } \\
\text { of propanediol } \\
\mathrm{mmol} / \mathrm{h}\end{array}$ \\
\hline $6 \cdot 6$ & $x \cdot 05$ \\
\hline 13.2 & $\mathrm{I} \cdot 55$ \\
\hline 26.4 & I.95 \\
\hline 52.8 & $4 \cdot 32$ \\
\hline
\end{tabular}

(Mcan rates between 2 and 4 h of incubation)

\begin{tabular}{ccc}
\multicolumn{3}{c}{ Products $(\mathrm{mmol} / \mathrm{h})$} \\
Acetate & Propionate & $n$-Propanol \\
0.27 & 0.32 & 0.50 \\
0.30 & 0.29 & 0.71 \\
0.53 & 0.28 & 0.85 \\
-0.37 & 0.17 & 0.69
\end{tabular}

* Containing $500 \mathrm{ml}$.

Effect of concentration of substrate. Some results of experiments in which the concentration of 1,2-propanediol was varied have already been reported (Czerkawski \& Breckenridge, 1972). In those experiments, neither propionaldehyde nor $n$-propanol was determined. The more complete results of a typical experiment, in which $300 \mathrm{ml}$ rumen contents and $200 \mathrm{ml}$ artificial saliva were incubated with various amounts of 1,2-propanediol are given in Table 3. The rates of utilization of the substrate and rates of formation of products increased with substrate concentration up to the concentration of $2.0 \mathrm{~g} /$ vessel. The highest concentration that was used $(4 \mathrm{~g} / \mathrm{vessel})$ resulted in some inhibition of formation of products, but not in disappearance of substrate. This could be of importance in practice (Waldo \& Schultz, I96o), since $4 \mathrm{~g} /$ $300 \mathrm{ml}$ rumen contents is equivalent to approximately $60 \mathrm{~g} /$ rumen of sheep. Thus, on the basis of the present results, when one contemplates the addition of this amount to the ration, one should not add it to a single meal.

Effect of concentration of rumen contents. Some of the results of a typical experiment, in which strained rumen contents were diluted with artificial saliva (100 $\mathrm{ml}$ ) and 
Table 4. Effect of concentration of rumen contents from sheep given sugar-beet pulp on the metabolism of 1,2-propanediol

(The results are the initial and final rates $(\mathrm{mmol} / \mathrm{h})$ measured at $2 \mathrm{~h}(\mathrm{I})$ and between 4 and $6 \mathrm{~h}$ of incubation $(\mathrm{F}))$

\begin{tabular}{|c|c|c|}
\hline \multirow{2}{*}{$\begin{array}{l}\text { Concentra } \\
\text { tion of } \\
\text { rumen } \\
\text { contents } \\
\text { (ml/ } \\
\text { vessel)* }\end{array}$} & \multicolumn{2}{|c|}{$\begin{array}{c}\text { Utilization } \\
\text { of } \\
\text { propanediol }\end{array}$} \\
\hline & I & $\mathrm{F}$ \\
\hline 100 & 0.35 & 0.21 \\
\hline 200 & 0.53 & 0.11 \\
\hline 300 & 0.74 & 0.07 \\
\hline 400 & 0.86 & 10 \\
\hline
\end{tabular}

\begin{tabular}{|c|c|c|c|c|c|c|c|}
\hline \multicolumn{8}{|c|}{ Products } \\
\hline \multicolumn{2}{|c|}{ Acetic } & \multicolumn{2}{|c|}{ Propionic } & \multicolumn{2}{|c|}{$n$-Propanol } & \multicolumn{2}{|c|}{ Propionaldehyde } \\
\hline I & F & I & $\mathrm{F}$ & I & $\mathrm{F}$ & I & $\mathbf{F}$ \\
\hline 0.07 & 0.05 & 0.03 & 0.07 & 0.12 & 0.13 & 0.06 & 0.02 \\
\hline 0.11 & 0.10 & 0.07 & 0.14 & 0.27 & 0.17 & 0.10 & -0.02 \\
\hline 0.26 & 0.39 & 0.17 & O.II & 0.38 & 0.13 & 0.14 & -0.16 \\
\hline 0.40 & 0.08 & 0.35 & 0.28 & 0.45 & 0.13 & -0 - I 6 & -0.07 \\
\hline
\end{tabular}

* Containing $500 \mathrm{ml}$.

Table 5. Effect of gaseous hydrogen on fermentation of 1,2-propanediol with rumen contents of sheep given sugar-beet pulp

\begin{tabular}{|c|c|c|c|c|}
\hline Additive & $\begin{array}{l}\mathrm{CH}_{4} \text { formed } \\
(\mathrm{ml})\end{array}$ & $\begin{array}{l}\mathrm{H}_{2} \text { used } \\
(\mathrm{ml})\end{array}$ & $\begin{array}{c}n \text {-Propanol } \\
(\mathrm{mmol} / \mathrm{vessel})\end{array}$ & $\begin{array}{l}\text { Propionic acid } \\
\text { (mmol/vessel) }\end{array}$ \\
\hline Control & 14.4 & 一 & - & 0.31 \\
\hline I'5 g diol & $8 \cdot 3$ & -- & $6 \cdot 25$ & $3 \cdot 13$ \\
\hline $100 \mathrm{ml} \mathrm{H}_{2}$ & $24 \cdot 7$ & $65 \cdot 5$ & - & 0.71 \\
\hline $\mathrm{I} \cdot 5 \mathrm{~g}$ diol $+100 \mathrm{ml} \mathrm{H}_{2}$ & I $5 \cdot 1$ & $70 \% 7$ & $6 \cdot 65$ & $2 \cdot 80$ \\
\hline
\end{tabular}

water up to a total volume of $500 \mathrm{ml}$, and incubated with $\mathrm{I} \cdot 0 \mathrm{~g} \mathrm{I,2-propanediol} \mathrm{for}$ $6 \mathrm{~h}$, are shown in Figs $\mathrm{I} a$ and $b$. In the same experiment, not shown in Fig. I, two other concentrations of rumen contents were used, namely 100 and $300 \mathrm{ml} / 500 \mathrm{ml}$ reaction mixture. The results are summatized in Table 4 . In general, the initial formation of products increased with the concentration of rumen contents, sometimes the rates being disproportionately large or small at high concentration of rumen contents. In the final stages of incubation, particularly when all or most of the substrate had been utilized, the concentrations of propionaldehyde decreased. It could be shown by extrapolation and from other experiments, that the maximum concentration of propionaldehyde occurred at about $6,45,3$ and $\mathrm{I} h$ with 20,40 , 60 and $80 \%$ inoculum respectively.

Effect of gaseous hydrogen on fermentation characteristics of 1,2-propanediol. Some of the results of a typical experiment are shown in Table 5. In this experiment $400 \mathrm{ml}$ rumen contents were incubated with $100 \mathrm{ml}$ artificial saliva, without additions, with ${ }^{\circ} 5 \mathrm{~g} \mathrm{r}, 2$-propanediol, with $100 \mathrm{ml}$ hydrogen in the gas phase or with both additions. There was no significant difference in the production of acetic acid and there was no difference in the utilization of propanediol. The diol increased hydrogen uptake and, as was shown previously, it inhibited methane production. Addition of hydrogen to the vessel in which propanediol was fermented resulted in increased production of $n$-propanol and decreased production of propionic acid. With hydrogen, the inhibition 
Table 6. Effect of 1,2-propanediol on inhibition of methane production by chloroform and accumulation of hydrogen gas during incubation with rumen contents of sheep given sugar-beet pulp

\begin{tabular}{|c|c|c|}
\hline & $\begin{array}{l}\text { Methane } \\
\text { production } \\
(\mathrm{ml} / \mathrm{h})\end{array}$ & $\begin{array}{c}\mathrm{H}_{2} \\
\underset{(\mathrm{ml} / \mathrm{h})}{\text { accumulation }}\end{array}$ \\
\hline $\begin{array}{l}\text { Expt I Control } \\
\quad+\mathrm{CHCl}_{3} \\
\quad+\mathrm{I}, 2-\mathrm{propanediol} \\
\quad+\mathrm{CHCl}_{3}+\mathrm{I}, 2 \text {-propanediol }\end{array}$ & $\begin{array}{l}4.05 \\
0.75 \\
3.35 \\
0.74\end{array}$ & $\begin{array}{l}0.04(0) \\
2.12(0) \\
0.04(2 \cdot 6) \\
0.2 .5(4 \cdot 1)\end{array}$ \\
\hline $\begin{array}{l}\text { Expt } 2 \text { Control } \\
\mathrm{CHCl}_{3} \\
\\
\text { 1,2-propanediol } \\
\mathrm{CHCl}_{3}+\mathrm{I}, 2 \text {-propanediol }\end{array}$ & $\begin{array}{r}17 \cdot 2 \\
2 \cdot 2 \\
14 \cdot 1 \\
1 \cdot 0\end{array}$ & $\begin{array}{l}0.10(7 \cdot 2) \\
5.20(21 \cdot 5) \\
0.10(7 \cdot 5) \\
3.20(5 \cdot 1)\end{array}$ \\
\hline
\end{tabular}

Expt I. $300 \mathrm{ml}$ rumen contents, $200 \mathrm{ml}$ artificial saliva, I-0 g r,2-propancdiol or $2 \mu \mathrm{CHCl}_{3}$ or both. No other substrate added. The ratios of the rate of production of $n$-propanol to propionic acid are given in parentheses.

Expt 2. $300 \mathrm{ml}$ rumen contents $+200 \mathrm{ml}$ artificial saliva, $0.5 \mathrm{~g} \mathrm{r,2-propanediol} \mathrm{or} 1 \mu \mathrm{l} \mathrm{CHCl} \mathrm{H}_{3}$ or both. Infused sodium formate at a constant rate of $120 \mathrm{mg} / \mathrm{h}$ in all vessels. The accumulation of sodium formate expressed in $\mathrm{mg} / \mathrm{h}$ is shown in parentheses.

\section{Table 7. Effect of oxygen on fermentation of $1,2-$ propanediol}

(The results are mean values after $4-6 \mathrm{~h}$ of incubation of $300 \mathrm{ml}$ rumen contents of sheep and $200 \mathrm{ml}$ artificial saliva with and without propanediol ( $\mathrm{I} \mathrm{g}$ ) or oxygen (100 ml). Each vessel also contained I g glucose)

\begin{tabular}{|c|c|c|c|c|c|c|c|c|}
\hline \multirow[b]{2}{*}{ Additive } & \multirow{2}{*}{$\begin{array}{l}\text { Pro- } \\
\text { panediol } \\
\text { used } \\
\text { (mmol) }\end{array}$} & \multicolumn{3}{|c|}{$\begin{array}{l}\text { Volatile fatty acids } \\
\text { (mmol) }\end{array}$} & \multicolumn{2}{|c|}{$\begin{array}{l}\text { Volatile neutral } \\
\text { compounds } \\
\text { (mmol) }\end{array}$} & \multicolumn{2}{|c|}{$\begin{array}{l}\text { Gases } \\
(\mathrm{ml})\end{array}$} \\
\hline & & Acetic & $\begin{array}{l}\text { Pro- } \\
\text { pionic }\end{array}$ & Butyric & $\begin{array}{c}\text { Propional } \\
\text { dehyde }\end{array}$ & $1 \frac{n-}{\text { Propanol }}$ & $\begin{array}{l}\mathrm{CH}_{4} \\
\text { produced }\end{array}$ & $\begin{array}{c}\mathrm{O}_{2} \\
\text { used }\end{array}$ \\
\hline None & - & 2.90 & $3 \cdot 10$ & $\mathrm{I} \cdot 85$ & - & - & $27 \cdot 0$ & - \\
\hline Propanediol & $12 \cdot I$ & 4.00 & 4.55 & $x \cdot 65$ & $1 \cdot 30$ & $5 \cdot 85$ & 15.1 & - \\
\hline Oxygen & $\longrightarrow$ & $4 \cdot 75$ & $3 \cdot 10$ & $2 \cdot 00$ & - & - & 10.2 & 16.8 \\
\hline Propanediol + oxygen & II' 5 & $4 \cdot 6 r$ & $3 \cdot 95$ & $I \cdot 65$ & 2.07 & 5.50 & $3 \cdot 6$ & $23 \cdot 4$ \\
\hline
\end{tabular}

There was net accumulation of polysaccharide of $0.40,0.83,1 \cdot 33$ and $1.03 \mathrm{mmol}$ in the four vessels respectively (expressed as hexose).

Carbon recovery from $\mathrm{I}, 2$-propanediol was: with $\mathrm{O}_{2} 57 \%$, without $\mathrm{O}_{2} 88 \%$.

of methane production was increased by $3.5 \mathrm{ml}$ and would make $14.0 \mathrm{ml}$ of hydrogen available together with the increased uptake of $5.2 \mathrm{ml}$, making $19.2 \mathrm{ml}$ or $0.85 \mathrm{mmol}$. Since the conversion of I mol propionic acid to $n$-propanol requires 2 mol hydrogen, the increased uptake of hydrogen $(0.85 \mathrm{mmol})$ agrees well with the changes in propionic acid and $n$-propanol $(0.40$ and $0.33 \mathrm{mmol}$ respectively).

These results cannot be taken as conclusive, for, although similar results were obtained in two other experiments of this type, in one further experiment, I,2-propanediol actually slightly depressed the uptake of gaseous hydrogen and in one there was no significant change of uptake. Thus, it seems that although the metabolism of I,2-propanediol requires a supply of hydrogen, it should be metabolic hydrogen rather than in gaseous form.

Effect of metabolic hydrogen on the metabolism of 1,2-propanediol. When methane 
'Table 8. Hydrogen balance in the incubation of 1,2-propanediol with rumen contents with and without oxygen

\begin{tabular}{lcc}
\multicolumn{3}{c}{$\left(\mathrm{mmol} \mathrm{H}_{2}\right.$ produced $(+)$ or used $\left.(-)\right)$} \\
\multicolumn{1}{c}{ Product } & Without $\mathrm{O}_{2}$ & With $\mathrm{O}_{2}$ \\
Acetate & +4.40 & -0.56 \\
Propionate & $+\mathrm{I} \cdot 45$ & +0.85 \\
Butyrate & $-\mathrm{I} \cdot 20$ & -2.10 \\
$n$-Propanol & -5.85 & -5.50 \\
$\mathrm{CH}_{4}$ & $-0.7 \mathrm{I}$ & -0.39 \\
Algebraic sum & $-\mathrm{I} \cdot 9 \mathrm{I}$ & -7.70 \\
Unaccounted substrate & $\mathrm{I} \cdot 45$ & 4.95 \\
mol $\mathrm{H}_{2}$ used/mol substrate & $\mathrm{I} \cdot 3$ & $\mathrm{I} \cdot 5$
\end{tabular}

production is inhibited by chloroform, there is an accumulation of hydrogen (cf. Czerkawski \& Breckenridge, I97I), but the amounts are less than expected. Therefore, it was of interest to know whether this hydrogen could be redirected to the I,2-propanediol metabolism. Some of the relevant results of two experiments are summarized in Table 6. In Expt I, there was considerable inhibition of methane production with chloroform and much less inhibition with 1,2-propanediol. Further, the chloroform inhibition resulted in accumulation of hydrogen, which was markedly reduced in the presence of $\mathrm{r}, 2$-propanediol. The addition of chloroform increased the ratio of $n$-propanol produced to propionic acid produced. In Expt 2, where methane production was increased by infusion of formate, similar results were obtained, but in the presence of propanediol, the reversal of the accumulation of hydrogen was less than in Expt $\mathrm{I}$. However, only $0.5 \mathrm{~g}$ of the diol was used in this experiment compared with $\mathrm{I} \cdot \mathrm{g}$ in Expt $\mathrm{r}$. Chloroform resulted in a small reduction of utilization of formate $(10 \%)$ and this was reversed when 1,2 -propanediol was present. In general, the presence of chloroform had little or no effect on the utilization of I,2-propanediol, but in some experiments the utilization was increased.

Effect of oxygen on the metabolism of 1,2-propanediol. The cxperimental procedure and some of the results of an experiment to investigate the effect of oxygen on the fermentation characteristics of propanediol are shown in Table 7 . The addition of oxygen to the gas phase made only little difference to the utilization of 1,2 -propanediol. It decreased the production of propionic and increased the production of acetic acid from the diol, increased the accumulation of propionaldehyde and decreased the production of $n$-propanol. Oxygen also inhibited methane production, and the uptake of oxygen increased when 1,2-propanediol was included in the incubation mixture. The recoveries of I,2-propanediol carbon without and with oxygen were 88 and $57 \%$ respectively. It was unlikely that the low recovery was due to deposition of storage polysaccharides; these were measured and included in the calculations. Also, at the end of the incubation ( $4-6 \mathrm{~h}$ ) all the glucose had been utilized. Oxygen is an acceptor of hydrogen, thus a competition for hydrogen would be expected to $(a)$ inhibit methane production, $(b)$ decrease the production of $n$-propanol and $(c)$ increase the accumulation of its precursor, propionaldehyde. An attempt to arrive at a hydrogen balance is shown in Table 8. To calculate the hydrogen balance it is necessary to assume simple 
reactions that probably do not really exist. The conversion of propanediol into most of the products considered here should result in net production of hydrogen (see the scheme in Fig. 2). Thus we would expect the following number of moles of hydrogen: propionate I, lactaldehyde I, lactate and acrylate 2, pyruvate 3 , acetate + carbon dioxide 4 , and $\frac{1}{2}$ butyrate + carbon dioxide 3 . The conversion of the diol into propionaldehyde is a simple dehydration. The conversion of propanediol to $n$-propanol results in the uptake of I mol hydrogen and the unlikely conversion to 3 mol methane would result in the uptake of $4 \mathrm{~mol}$ hydrogen. The net uptake of hydrogen during incubation without oxygen and the large net uptake of hydrogen when oxygen was added to the gas phase were roughly proportional to the amounts of unaccounted substrate utilized. These results suggest that some of the diol is reduced to an unknown product other than $n$-propanol, and that the amount of this substance is increased when the diol is incubated under oxygen.

In other similar experiments, where two levels of oxygen were used, the propionaldehyde concentrations increased due to addition of oxygen in early stages of reaction only. Other changes were similar to those observed in Table 7 , but were of smaller magnitude.

\section{DISCUSSION}

\section{Metabolic pathways}

It was known a long time ago that rhamnose is cleaved to dihydroxyacetone and lactaldehyde, and it was shown by Kluyver \& Schnellen (1937) that I,2-propanediol was one of the main products in the digestion of rhamnose by a bacterium, other products being acetic, succinic and formic acids.

On the basis of the results reported here and those reported previously (Czerkawski \& Breckenridge, 1972), it is possible to devise a tentative scheme for the metabolic pathways involved in the dissimilation of $\mathrm{x}, 2$-propanediol and rhamnose in the rumen. This is shown in Fig. 2, where tentative reactions are marked by broken arrows. It has been shown conclusively that $\mathrm{I}, 2$-propanediol is converted into propionaldehyde and this in turn is reduced to $n$-propanol. It is not certain whether the propionic acid is produced direct from propionaldehyde, or from propanol or more indirectly through lactaldehyde, lactate and acrylate. It was shown here and more direct in previous experiments (Czerkawski \& Breckenridge, 1972) that $n$-propanol can be converted into propionic acid with stoichiometric production of methane. Clearly, some of the diol is converted to propionic acid, therefore one or more of the three tentative pathways might really operate.

In comparative experiments, not reported here, the fermentation of rhamnose resulted in production of both propionaldehyde and $n$-propanol, though in smaller amounts than those obtained from propanediol (with propanediol, 0.49 and $\mathrm{r} .05 \mathrm{mmol} /$ $\mathrm{h}$ of propionaldehyde and propanol respectively; with rhamnose, 0.08 and $0.2 \mathrm{Immol} / \mathrm{h}$ of propionaldehyde and propanol respectively). There is no other pathway from rhamnose to propionaldehyde and $n$-propanol than through lactaldehyde and it must be accepted that lactaldehyde is an intermediate in dissimilation of rhamnose, and that it can be reduced to I,2-propanediol, but there is no direct evidence of the reverse 


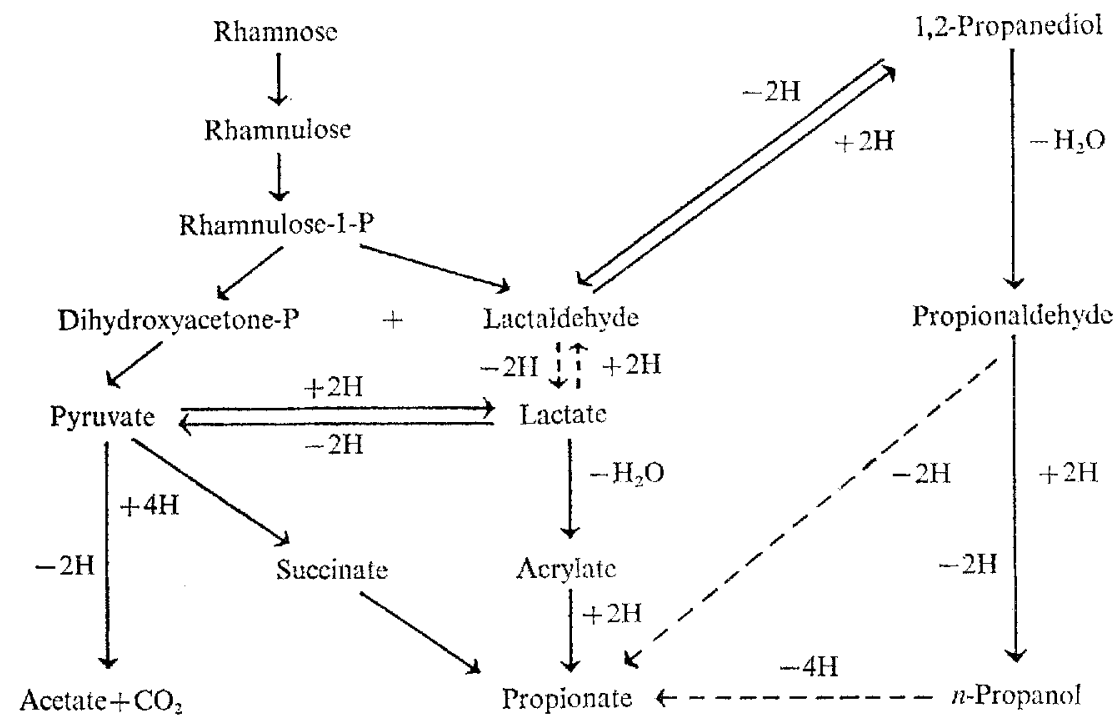

Fig. 2. Tentative scheme for the metabolism of rhamnose and 1,2-propanediol in the rumen. The broken arrows indicate that there is no conclusive expcrimental evidence for these reactions.

reaction. There is also no direct evidence of the interconversion of lactaldehyde and lactic acid. However, the existence of such reactions would help to explain the formation of acetic acid during incubation of I,2-propanediol with rumen contents. Nevertheless, it is possible that acetic acid is formed from propionic acid by reversal of the succinate pathway.

The proposed scheme gives a general picture of the metabolism of rhamnose and I,2-propanediol, but it tells us nothing about the energetics of the various reactions and whether they occur in a single micro-organism or in related groups of microorganisms. These problems will require a considerable amount of further work.

\section{Conditions of fermentation}

It was demonstrated that although the rate of dissimilation of I,2-propanediol by rumen micro-organisms increases with the concentration of substrate, it shows a maximum beyond which the rate of formation of products declines and the diol actually begins to interfere with the basal rumen fermentation. The maximum amounts might be greater than calculated on the basis of the present results, because the rumen contents are in a state of flux and because the diol might be absorbed directly through the rumen wall and metabolized in the liver.

The rate of dissimilation of I,2-propanediol also depended upon the concentrations of rumen micro-organisms. It was shown conclusively that the main intermediate in the conversion of the diol into $n$-propanol is propionaldehyde, but extrapolation of the present results indicates that with undiluted rumen contents from animals on a suitable diet, with moderate concentration of substrate, the increase in the concentration of the aldehyde would be ephemeral. The reaction I,2-propanediol $\rightarrow n$ - 
propanol makes the diol an acceptor of excess metabolic hydrogen, and it is this that could make I,2-propancdiol so useful in situations where the normal, though wasteful, scavenger of excess hydrogen - namely methanogenesis - is inhibited. The present results indicate that with undiluted rumen contents and moderate amounts of diol, the conversion into $n$-propanol is likely to go further, and lead to the production of propionic acid and net production of hydrogen and, ultimately, methane. Although I,2-propanediol can successfully compete with the methanogenic system for metabolic hydrogen, its dissimilation results in a relatively small uptake of hydrogen compared with methanogenesis (Clapperton \& Czerkawski, I972a). This, together with the limitations discussed above, make it unsuitable as an inhibitor of methane production. However, when methane production is inhibited by some other means, for instance, by administration of chloroform, the presence of propanediol might be very useful in that its metabolism would utilize the relatively small amounts of hydrogen associated with such inhibition (Clapperton \& Czerkawski, 1972b). Whether 1,2-propanediol is absorbed as such or absorbed as propionic acid or $n$-propanol, the result is increased glucogenesis, although the oxygen requirement and energetic efficiency may vary.

The increased oxygen uptake during dissimilation of 1,2-propanediol in spite of the fact that the reaction is in effect a hydrogen-accepting system, leads to a speculation that the organisms that metabolize the diol are facultatively aerobic. It is concluded that under normal conditions that obtain in the rumen, 1,2 -propanediol is metabolized as suggested in the scheme (Fig. 2), but under certain conditions, such as partial aerobiosis, some other unknown pathways are involved.

Finally, the ability of rumen micro-organisms to dissimilate 1,2-propanediol depends on the diet of the host animal. On the basis of the limited number of diets investigated, molassed sugar-beet pulp appears to be the diet of choice. It might be pertinent to note that the molassed sugar-beet pulp contains an unusually high proportion of rhamnose, a sugar whose fermentation appears to be related to that of I,2-propanediol.

We are grateful for the expert assistance of Mrs C. Faulds.

\section{REFERENCES}

Abeles, R. H. \& Lee, H. A. Jr (196I). F. biol. Chem. 236, 2347.

Brownstein, A. M. \& Abeles, R. H. (I961). F. biol. Chem. 236, 1999.

Clapperton, J. L. \& Czerkawski, J. W. (1972a). Br. F. Nutr. 27, 553.

Clapperton, J. L. \& Czerkawski, J. W. (1972b). Proc. Nutr. Soc. 31, 55A.

Conway, E. J. (1962). Microdiffusion Analysis and Volumetric Error, p. 234. London: Crosby, Lockwood and Son.

Cottyn, B. G. \& Boucque, C. V. (1968). J. agric. Fd Chem. 16, 105.

Czerkawski, J. W. (1966). Br. F. Nutr. 20, 833 .

Czerkawski, J. W. \& Breckenridge, G. (1969). Br. F. Nutr. 23, 5 I.

Czerkawski, J. W. \& Breckenridge, G. (1970). Lab. Pract. 19, 717.

Czerkawski, J. W. \& Breckenridge, G. (1971). Lab. Pract. 20, 403.

Czerkawski, J. W. \& Breckenridge, G. (1972). Br. F. Nutr. 27, I 3 I.

Czerkawski, J. W. \& Clapperton, J. L. (1968). Lab. Pract. 17, 994.

Emery, R. S., Burg, N., Brown, L. D. \& Blank, G. N. (1964). F. Dairy Sci. 47, 1074.

Emery, R. S., Brown, R. E. \& Black, A. T. (1967). F. Nutrition 92, 348.

Huff, E. (1959). Analyt. Chem. 31, 1626. 
Huff, E. \& Rudney, H. (1959). F. biol. Chem. 234, 1 o6o.

Jones, L. R. \& Riddick, J. A. (1957). Analyt. Chem. 29, I2I4.

Kluyver, A. J. \& Schnellen, C. (1937). Enzymologia 4, 7.

Ladd, J. N. \& Walker, D. J. (1959). Biochem. F. 71, 365.

McDougall, E. I. (1948). Biochem. F. 43, 99.

Noble, R. C. \& Czerkawski, J. W. (I 972). Analyst (in the Press).

Rudney, H. (1950). Archs Biochem. 29, 23 I.

Rudney, H. (r954). F. biol. Chem. 210, 361.

Shull, K. H. \& Miller, O. N. (ro60). F. biol. Chem. 235, $55^{1}$.

'Ting, S.-M., Sellinger, O. Z. \& Miller, O. N. (1964). Biochim. biophys. Acta 89, 217.

Toraya, T., Sugimoto, Y., Tamao, Y., Shimizu, S. \& Fukui, F. (197 I). Biochemistry, N. Y. 10, 3475.

Vogel, A. I. (195I). Practical Organic Chemistry. London, New York and Toronto: Longman, Green and $\mathrm{Co}$.

Waldo, D. R. \& Schultz, L. H. (1960). F. Dairy Sci. 43, 496. 